EDITORIALS

\title{
Disparities in Health and Health Care
}

\section{Moving from Describing the Problem to a Call for Action}

\author{
Carol M. Mangione, MD, MSPH, Eileen Reynolds, MD
}

D uring the past two decades the overall health of the nation has improved. However, the dramatic disparities in the morbidity and mortality experienced by African Americans, Latinos, Native Americans, Asians, and Pacific Islanders provide compelling evidence that many Americans have not experienced this health dividend. ${ }^{1}$ Disparities in health and in access to health care have been documented repeatedly across a broad range of medical conditions and for a wide variety of traditionally disadvantaged groups such as those in racial or ethnic minorities, women, and older persons. These differences have been noted in health outcomes such as quality of life $^{2,3}$ and mortality, ${ }^{4-10}$ processes of care such as utilization of cardiac procedures after myocardial infarction $^{6,7,11-15}$ or access to primary prevention, ${ }^{16,17}$ quality and appropriateness of care, ${ }^{18-24}$ and the prevalence of common chronic medical conditions. ${ }^{25}$

The recent national effort to eliminate health disparities by the year 2010 has been spearheaded by the Surgeon General and is a critical component in the President's Federal Initiative on Race (http:// raceandhealth.hhs.gov/). The infusion of resources at the federal level will accelerate the acquisition of new knowledge about the causes of disparities in health and the development of interventions designed to eliminate disparities. Variation in health by demographic characteristics is an end product of barriers to a healthy lifestyle and to health care at multiple levels, including community, health care system, health insurance, providerlevel and patient-level characteristics. Researchers are just beginning to study the relative importance of each contributing factor and to develop interventions designed to eliminate disparities in health.

This issue of the Journal includes 6 articles that focus on patient-level and provider-level characteristics that are associated with variation in health outcomes such as physical disability, ${ }^{26}$ symptoms $^{27}$ and patient satisfaction $^{28}$ or processes of care such as the treatment of pain, ${ }^{29}$ evaluation and treatment of abdominal pain ${ }^{30}$; and use of invasive procedures after myocardial infarction. ${ }^{31}$ This editorial will first consider the papers by Iezzoni, Barsky, and Stein, which focus on the characteristics of patients as correlates of outcomes and process of care. It will then discuss the themes and implications of the papers by Derose, Weisse, and Wigton which focus on the characteristics of physicians and the roles that they 276 may play in patient satisfaction and variation in processes of care.

In a carefully constructed analysis of data from the disability supplement of the National Health Interview Survey (NHIS-D), Iezzoni et al. provide gender-, race-, and age-specific estimates of disability. ${ }^{26}$ The estimates of disability were based on the responses to 3 simple questions about walking, climbing stairs, and standing for 20 minutes. Surprisingly, 10\% of the population studied reported some mobility difficulty, and the adjusted rates of disability were significantly higher for women at $11.8 \%$ versus $8.8 \%$ for men and for African Americans at $15 \%$ versus $10 \%$ for whites. Mobility difficulties were more likely in those who were poorly educated, living alone, living in poverty, or experiencing vision or balance problems or symptoms of anxiety or depression, emphasizing the high level of vulnerability among such groups.

Although data identifying the underlying causes for the reported disability were limited, it is not surprising that many of the conditions identified such as arthritis, accidents, and cardiovascular disease disproportionately affect women and/or persons from racial and ethnic minorities, ${ }^{1,25}$ suggesting that the higher rates of disability for women and African Americans may represent the final common pathway from many conditions that disproportionately affect these groups.

In a qualitative review of 175 articles, Barsky et al. report what is known about gender differences with regard to somatic symptoms. ${ }^{27}$ Their main findings indicate that women experience more numerous, frequent, and more intense bodily symptoms than do men. This appears to be the case when all symptoms are considered, when reproductive or gynecological symptoms are excluded, and when the analyses are restricted to unexplained symptoms. Importantly, the authors acknowledge that the observed gender differences are likely to be affected by ethnicity, race, upbringing, and personality. It is also likely that environment, culture, socioeconomic status, and gender congruence between provider and patient modify the relation between gender and symptoms. Few if any of the articles included in the review took these characteristics into consideration.

Potential explanatory variables for the observed differences by gender in somatic symptoms included evidence that women have two to three times higher rates of anxiety and depression, and 8 to 25 times higher rates 
of current or past physical abuse and trauma. Additionally, women and men seem to differ in their thresholds for judging and considering a sensation to be noxious. This finding raises questions about whether women and men with the same medical condition would present with differing constellations of symptoms. For the practicing physician, symptoms provide diagnostic clues to underlying diseases and also need treatment in their own right. The findings from this review suggest that once the common organic problems for a given set of symptoms have been ruled out, the physician should conduct a careful interview to determine whether treatable conditions such as anxiety or depression may be the underlying cause of the somatic complaints.

The third paper in this group used prospectively collected data from 5 community hospitals in Michigan to examine the influence of patient-level characteristics on use of invasive cardiovascular procedures after acute myocardial infarction (AMI). ${ }^{31}$ A number of landmark papers have documented variation in use of invasive cardiac procedures by gender and ethnicity. ${ }^{7,8,11-15}$ In this paper, Stein et al. confirm that white women were offered coronary artery bypass grafting (CABG) less frequently than white men, even after adjusting for severity of disease and cardiac catheterization results.

Definitive conclusions about the care that African Americans received could not be made because of small sample size. However, when compared to white men, there was a trend toward African-American women being offered percutaneous transluminal coronary angioplasty (PTCA) less often and a trend toward African-American men being offered CABG less often. The authors emphasize that the proportion of participants with a left main artery stenosis and or stenoses in 3 or more vessels was similar across both genders and racial groups, suggesting that the rates of offering PTCA and CABG should have been similar across the study. Care must be taken when interpreting the findings about the role of race in this study because $>50 \%$ of the African-Americans participants were cared for in the hospital that had the lowest rate of performing cardiac catheterizations among the 5 participating facilities. This leaves open the possibility that variation in use of invasive cardiac procedures attributed to race may be a function of some other characteristic of the hospital such as limited capacity to perform cardiac procedures. Although it is impossible to know from the data presented what the most appropriate rate of invasive procedures is after AMI, the observation that African Americans were clustered in the facility with the lowest rates of use of thrombolysis and cardiac catheterization suggests that the most accessible hospital for this group may have been of lower quality.

Over the past decade, much of the focus of research on disparities in health has moved from descriptions of variation in health or healthcare to an exhaustive search for explanatory or intervening variables that account for observed disparities in health and process of care for marginalized groups in our society. Variables that have been examined in great detail include the role of health insurance, ${ }^{23,32-40}$ and the types of facilities where care is administered. ${ }^{5,6}$ Central to this line of inquiry is the potential role of the physician for mitigating or exacerbating disparities in health and care provided. Both the fixed traits of physicians such as gender or ethnicity and learned traits such as biases or stereotypes have been examined. ${ }^{4-45}$ The papers by Derose et al. and Weisse et al. specifically examine the influence of physician gender on patient satisfaction and variation in management of pain, respectively; and the third paper, by Wigton et al., examines whether physicians' biases toward obesity influence the evaluation and treatment of abdominal pain.

To assess the influence of physicians' gender on patient satisfaction, Derose et al. collected data from a sample of English- and Spanish-speaking patients who were seen in the Emergency Department (ED) of a public hospital for nonurgent problems. The authors specifically examined the influence of physician gender on ratings of 5 interpersonal aspects of care, trust of the physician, and overall rating of the physician by female and male patients. $^{28}$

The main findings from this study indicate that women patients trusted female physicians more and rated them more positively overall. Female physicians were rated higher on time spent and amount of concern shown by female patients whereas male patients provided similar ratings for both female and male physicians. Although the positive influence of gender concordance between physician and patient on patient satisfaction has been noted before, ${ }^{46-48}$ this paper is one of the first to study this question in a predominantly Spanish-speaking, lowincome sample. As noted by the authors, understanding the determinants of patient satisfaction and particularly trust, may be a critical step in eliminating health disparities, since level of trust has been shown to be a determinant of patient adherence and improved health status. ${ }^{49}$ The work of Morales et al. ${ }^{50}$ has demonstrated that language spoken and acculturation can influence patient satisfaction scores, emphasizing the importance of measuring the determinants of satisfaction across demographic groups. It is uncertain whether efforts to modify the communication styles of male physicians could improve the satisfaction of female patients or whether beliefs such as trust are so strongly determined by cultural experiences that efforts are better directed at developing a demographically diverse physician work force.

The goals of the study reported by Weisse et al. were to determine whether patients' gender and race affect physicians' decisions about pain management for renal colic and chronic back pain and to determine whether the relationship of patient gender and race to aggressiveness of pain management was influenced by the gender of the treating physician. ${ }^{29}$ The investigators presented 3 hypothetical scenarios to a convenience sample of 111 Northeastern primary care physicians. The majority of 
participants were attending physicians $(n=98)$ and the study had a 50\% response rate. Although there was adequate representation of both female and male physicians, $79 \%$ of the participants were white, precluding any analyses of the role of physicians' race on treatment decisions. The vignettes included acute renal colic, representing severe but self-limited pain; back pain, representing chronic pain with greater possibility that narcotic addiction could become an issue; and management of sinusitis as the "control" condition. Symptom presentation and severity were held constant and race/ gender varied. Physicians were given the opportunity to provide a prescription for hydrocodone and acetaminophen in combination at a variety of strengths, dosing intervals, and days. A balanced design was employed where each physician completed 3 cases, which were randomly assigned to be white or African American and male or female.

No overall differences with respect to race and gender were found with regard to the decision to treat or the amount of pain medicine administered. However, when the role of physician gender was taken into consideration, male physicians prescribed higher doses of pain medications to whites as compared to African Americans and women physicians were more likely to prescribe higher doses to African Americans. In summary, gender and racial differences in pain management were only evident when the gender of the physician was taken into consideration.

Although the sinusitis case was included primarily to mask the subjects from the study hypotheses, it is interesting to note that white patients were prescribed longer courses of antibiotics and were given refills at the time of follow-up more often than African-American patients. Additionally, male patients were more likely to be prescribed a more expensive antibiotic with broader coverage.

Case vignette methodology is an attractive approach for studying the role of physician characteristics on process of care because it holds many potential confounding aspects of the clinical presentation constant. Whether performance on the vignette truly represents how decisions about pain management would be made in an actual encounter is difficult to know. Additionally, this approach does not provide any information about whether patients are actually receiving the appropriate dose of pain medicine. These underlying differences in management by physician gender are difficult to explain. The authors hypothesize that male physicians may sympathize or identify with patients of the same gender or race and female physicians may identify with disadvantaged groups in general. Further descriptive work in this area is needed before we can develop interventions to ensure that all patients receive appropriate pain management.

Most of the descriptive research on disparities in health and healthcare has focussed on the role of demographic characteristics rather than on physical traits such as obese appearance. However, obesity is a stigmatized trait in our society, is more prevalent among disadvantaged groups such as African-American women and Latinas, ${ }^{51-53}$ and confers higher risk for breast cancer, cervical cancer, diabetes, and cardiovascular disease. ${ }^{25,54,55}$ Additionally, recent reports by Wee et al. and others demonstrate that overweight and obese women in primary care settings are less likely to be screened for cervical and breast cancer. ${ }^{56,57}$ For these reasons, it is important to know whether patients who are obese receive lower quality of care because of biases on the part of their physicians.

The paper by Wigton et al. begins to address this question with the results from an experiment where videotapes of simulated patients were shown to thirdand fourth-year medical students to determine whether obese appearance alone would affect the diagnosis and management of abdominal pain. ${ }^{30}$ In addition to making management recommendations, the medical students were also asked to grade whether they felt the patients were attractive or not and the likelihood that they would comply with recommended treatments.

As noted by the authors, it is reassuring that the main results showed no difference in the tests or treatments ordered for the obese versus the nonobese patients except for where it may have been more appropriate. However, the students rated the obese patients as less attractive, less compliant, and more depressed. They also indicated that they would be less likely to want these patients to be in their continuity-of-care practices. It seems likely that in actual clinical settings these negative perceptions would adversely influence doctor-patient communication, collaborative goal setting, treatment plans, and ultimately the quality of care delivered. The negative views expressed about obese persons by these students are congruent with the stereotypes in our society and present a particular challenge for medical educators. Further research is needed to determine the relative importance of addressing physician-level characteristics if we are to meet our national goal of eliminating disparities in health by 2010 .

Taken in the aggregate, these 6 papers contribute to a growing literature that describes patient-level and physician-level characteristics that are associated with variation in health and process of health care. If we are to accomplish the goal of eliminating disparities in health, we will need to move onto the development of multidimensional and multilevel interventions that are targeted toward groups in our society who are at greatest risk for poor health outcomes.

It is our firm belief that eliminating disparities in health and healthcare cannot be accomplished without the attention and participation of primary care physicians. Therefore the SGIM program committee has selected the theme of the 2001 National SGIM meeting to be "Disparities in Health and Healthcare: Roles for General Internists". In addition to all of the expected content in the areas of clinical epidemiology, health services research, 
medical education, and clinical care, we invite you to attend this meeting and hear first hand from the Surgeon General, Dr. David Satcher, why eliminating disparities in health is a critical component of the national health agenda. We hope that attendees will also learn about the scope of the problem, hear about new research findings that describe clinical interventions designed to decrease disparities in health, and learn new teaching and clinical methods in the areas of cultural competence and patient communication. We believe that the 2001 program committee has put together an excellent meeting that should energize us all to play a more active role in eliminating disparities in health and healthcare.-CARol M. Mangione, MD, MSPH, UCLA School of Medicine, Department of Medicine, Los Angeles Calif., and the RAND Health Program, Santa Monica, Calif. and EILEen Reynolds, MD, Harvard Medical School, Department of Medicine at Beth Israel Deaconess Medical Center, Boston, Mass.

\section{REFERENCES}

1. Kirschstein RL, Ruffin J. Strategic research plan to reduce and ultimately eliminate health disparities, National Institutes of Health, U.S. Department of Health and Human Services, Oct 2000.

2. Ware JE, Rogers WH, Davies AR, et al. Comparison of health outcomes at a health maintenance organization with those of feefor-service care. Lancet. 1986; May 3:1017-22.

3. Cunningham WE, Hays RD, Williams KW, Beck KC, Dixon WJ, Shapiro MF. Access to medical care and health-related quality of life for low-income persons with symptomatic human immunodeficiency virus. Medical Care. 1995;33:739-54.

4. Cooper R, Cutler J, Desvigne-Nickens P, et al. Trends and disparities in coronary heart disease, stroke, and other cardiovascular diseases in the United States: findings of the national conference on cardiovascular disease prevention. Circulation. (Online) 2000; 102:3137-47.

5. Gordon HS, Harper DL, Rosenthal GE. Racial variation in predicted and observed in-hospital death: a regional analysis. JAMA. 1996;276:1639-44.

6. Kahn KL, Pearson ML, Harrison ER, et al. Health care for black and the poor hospitalized Medicare patients. JAMA. 1994;271: 1169-74.

7. Udvarhelyi IS, Gatsonis C, Epstein AM, Pashos CI, Newhouse JP, McNeil BJ. Acute myocardial infarction in the Medicare population. Process of care and clinical outcomes. JAMA. 1992;268: 2530-6.

8. Peterson ED, Wright SM, Daley J, Thibault GE. Racial variation in cardiac procedure use and survival following acute myocardial infarction in the Department of Veterans Affairs. JAMA. 1994;271: 1175-80.

9. Cooper GS, Yuan Z, Landefeld CS, Rimm AA. Surgery for colorectal cancer: race-related differences in rates and survival among Medicare beneficiaries. Am J Public Health. 1996;86(4):582-6.

10. Bach PB, Cramer LD, Warren JL, Begg CB. Racial differences in the treatment of early-stage lung cancer. N Engl J Med. 1999;341: 1198-205.

11. Ayanian JZ, Epstein AM. Differences in the use of procedures between women and men hospitalized for coronary artery disease. N Engl J Med. 1991;325:22 1-5.

12. Krumholz HM, Douglas PS, Lauer MS, Pasternak RC. Selection of patients for coronary angiography and coronary revascularization early after myocardial infarction: is there evidence for gender bias? Ann Intern Med. 1992;116:785-90.
13. Ayanian JZ, Udvarhelyi IS, Gatsonis CA, Pashos CL, Epstein AM. Racial differences in the use of revascularization procedures after coronary angiography. JAMA. 1993;269:2642-6.

14. Whittle J, Congliaro J, Good CB, Lofgren RP. Racial differences in the use of invasive cardiovascular procedures in the Department of Veteran's Affairs medical system. N Engl J Med. 1993; 329:621-7.

15. Carlisle DM, Leake BD, Shapiro MF. Racial and ethnic disparities in the use of cardiovascular procedures: associations with type of insurance. Am J Public Health. 1997;87:263-7.

16. Makuc DM, Breen N, Freid V. Low income, race, and the use of mammography. Health Serv Res. 1999;34(1 Pt 2):229-39.

17. Hayward RA, Shapiro MF, Freeman HE, Corey CR. Who gets screened for cervical and breast cancer? Results from a new national survey. Arch Intern Med. 1988;148:1177-81.

18. Johnson PA, Lee TH, Cook EF, Rouan GW, Goldman L. Effect of race on the presentation and management of patients with acute chest pain. Ann Intern Med. 1993;118:593-601.

19. Murray-Garcia JL, Selby JV, Schmittdiel J, Grumbach K, Quesenberry CP. Racial and ethnic differences in a patient survey: patients' values, ratings, and reports regarding physician primary care performance in a large health maintenance organization. Med Care. 2000;38:300-10.

20. Taira DA, Safran DG, Seto TB, et al. Asian-American patient ratings of physician primary care performance. J Gen Intern Med. 1997; 12:237-42.

21. Escarce JJ, Epstein KR, Colby DC, Schwartz JS. Racial differences in the elderly's use of medical procedures and diagnostic tests. Am J Public Health. 1993;340:618-26.

22. Retchin SM, Brown B. The quality of ambulatory care in Medicare health maintenance organizations. J Public Health. 1990;80: 411-5.

23. Retchin SM, Clement DG, Rossiter LF, Brown B, Brown R, Nelson L. How the elderly fare in HMOs: outcomes from the medicare competition demonstrations. Health Serv Res. 1992; 27:651-68.

24. Clement DG, Retchin SM, Brown RS, Stegall MH. Access and outcomes of elderly patients enrolled in managed care. JAMA. 1994;271:1487-92.

25. Kass BL, Weinick MN, Monheit AC. Racial and ethnic differences in health, 1996. Agency for Health Care Policy and Research, 1999. MEPS Chartbook No. 2. AHCPR Pub. No. 99-0001.

26. Iezzoni LI, McCarthy EP, Davis RB, Siebens H. Mobility difficulties are not only a problem of old age. J Gen Intern Med. 2001;16: 235-43.

27. Barsky AJ, Peekna HM, Borus JF. Somatic symptom reporting in women and men. J Gen Intern Med. 2001;16:266-75.

28. Derose KP, Hays RD, McCaffrey DF, Baker DW. Does physician gender affect satisfaction of men and women visiting the emergency department? J Gen Intern Med. 2001;16:218-26.

29. Weisse CS, Sorum PC, Sanders KN, Syat BL. Do gender and race affect decisions about pain management? J Gen Intern Med 2001;16:211-7.

30. Wigton RS, McGaghie WC. The effect of obesity on medical students' approach to patients with abdominal pain. J Gen Intern Med 2001;16:262-5.

31. Watson RE, Stein AD, Dwamena FC, et al. Do race and gender influence the use of invasive procedures? J Gen Intern Med. 2001;16:227-34.

32. Manning WG, Newhouse JP, Duan N, et al. Health insurance and the demand for medical care. Am Econ Rev. 1987;77:251-77.

33. Brook RH, Ware JE, Rogers WH, et al. Does free care improve adults' health? N Engl J Med. 1983;309:1426-34.

34. Lurie N, Kamberg CJ, Brook RH, Keeler EB, Newhouse JP. How free care improved vision in the Health Insurance Experiment. Am J Public Health. 1989;79:640-2.

35. Miller RH, Luft HS. Managed care plan performance since 1980. JAMA. 1994;271:1512-9. 
36. Johnson AN, Dowd B, Morris NE, Lurie N. Differences in patient resource use by type of health plan. Inquiry. 1989;26:388-98.

37. Wells KB, Hays RD, Burnam MA, Rogers W, Greenfield S, Ware JE Jr. Detection of depressive disorder for patients receiving prepaid or fee-for-service care: results from the Medical Outcomes Study. JAMA. 1989;262:3298-302.

38. Rogers WH, Wells KB, Meredith LS, Sturm R, Burnam MA. Outcomes for adult outpatients with depression under prepaid or fee-for-service financing. Arch Gen Psychiatry. 1993;50:517-25.

39. Carlisle DM, Siu AL, Keeler EB, et al. HMO vs. fee-for-service care of older persons with acute myocardial infarction. Am J Public Health. 1992;82:1626-30.

40. Kahn KL, Rubenstein LV, Draper D, et al. The effects of the DRGbased prospective payment system on quality of care for hospitalized Medicare patients: an introduction to the series. JAMA. 1990;264:1953-5.

41. Bertakis KD, Helms LJ, Callahan EJ, Azari R, Robbins JA. The influence of gender on physician practice style. Med Care. 1995; 33:407-16

42. Saha S, Taggart SH, Komaromy M, Bindman AB. Do patients choose physicians of their own race? Health Aff (Millwood). 2000; 19:76-83.

43. Schmittdiel J, Grumbach K, Selby JV, Quesenberry CP. Effect of physician and patient gender concordance on patient satisfaction and preventive care practices. J Gen Intern Med. 2000;15: 761-9.

44. Roter DL, Geller G, Bernhardt BA, Larson SM, Doksum T. Effects of obstetrician gender on communication and patient satisfaction. Obstet Gynecol. 1999;93(5 Pt 1):635-41.

45. Schulman KA, Berlin JA, Harless W, et al. The effect of race and sex on physicians' recommendations for cardiac catheterization. N Engl J Med. 1999;340:618-26.

46. Cooper-Patrick L, Gallo JJ, Gonzales JJ, et al. Race, gender, and partnership in the patient-physician relationship. JAMA. 1999;282:583-9
47. Morales LS, Cunningham WE, Brown JA, Liu H, Hays RD. Are Latinos less satisfied with communication by health care providers? J Gen Intern Med. 1999;14:409-17.

48. Perez-Stable EJ, Naapoles-Springer A, Miramontes JM. The effects of ethnicity and language on medical outcomes of patients with hypertension or diabetes. Medical Care. 1997;35:1212-9.

49. Safran DG, Taira DA, Rogers WH, Kosinski M, Ware JE, Tarlov AR. Linking primary care performance outcomes of care. J Fam Pract. 1998;47:213-20.

50. Morales LS, Weech-Maldonado R, Spritzer KL, Elliott MN, Hays RD. Differences in CAHPS adult survey ratings and reports by race and ethnicity: an analysis of the national CAHPS benchmarking data 1.0. Health Services Research. 2001; In press.

51. Shankar S, Nanda JP, Bonney G, Kofie V. Obesity differences between African-American men and women. J Natl Med Assoc. 2000;92:22-8.

52. Okosun IS, Prewitt TE, Cooper RS. Abdominal obesity in the United States: prevalence and attributable risk of hypertension. J Hum Hypertens. 1999; 13:425-30.

53. Gillum RF. Distribution of waist-to-hip ratio, other indices of body fat distribution and obesity and associations with HDL cholesterol in children and young adults aged 4-19 years: The Third National Health and Nutrition Examination Survey. Int J Obes Relat Metab Disord. 1999;23:556-63.

54. Allison DB, Fontaine KR, Manson JE, Stevens J, Vanltallie TB. Annual deaths attributable to obesity in the United States. JAMA. 1999;282:1583-8.

55. Garfinkel L. Overweight and cancer. Ann Intern Med. 1985;103: 1034-6.

56. Wee CC, McCarthy EP, Davis RB, Phillips RS. Screening for cervical and breast cancer: is obesity an unrecognized barrier to preventive care? Ann Intern Med. 2000;132:697-704.

57. Fontaine KR, Faith MS, Allison DB, Cheskin LJ. Body weight and health care among women in the general population. Arch Fam Med. 1998;7:381-4. 